\title{
Assessment of fracture risk in women with breast cancer using current vs emerging guidelines
}

\author{
P Hadji, ${ }^{*}$, M Ziller', US Albert ${ }^{2}$ and M Kalder ${ }^{2}$ \\ 'Department of Endocrinology, Reproductive Medicine, and Osteoporosis, Philipps-University of Marburg, Baldingerstrasse 35033, Marburg, Germany; \\ ${ }^{2}$ Department of Gynaecology, Gynaecological Endocrinology and Oncology, Philipps-University of Marburg, Baldingerstrasse 35033, Marburg, Germany
}

BACKGROUND: Breast cancer (BC) therapies can have negative effects on bone. Current guidelines recommend antiresorptive therapy based on bone mineral density (BMD), and emerging guidelines include both clinical risk factors and BMD to assess the overall fracture risk. A retrospective, case-controlled study based on current and emerging guidelines was conducted in women with newly diagnosed $\mathrm{BC}$ to identify those who were at increased fracture risk based on current and emerging guidelines.

METHODS: Baseline characteristics, fracture risk factors, and lumbar-spine (LS) and total-hip BMD in women with BC (88 premenopausal and 402 postmenopausal) were assessed to determine who would receive bisphosphonate therapy based on current and emerging guidelines.

RESULTS: Among patients with estrogen-receptor-positive $\left(E R^{+}\right)$BC, I 8.8\% of premenopausal and 36.9\% of postmenopausal women were osteopenic at LS. In the postmenopausal cohort, osteoporosis was more prevalent in patients with $\mathrm{ER}^{+}$vs $\mathrm{ER}^{-} \mathrm{BC}$. Current guidelines identified $8.9 \%$ of patients as eligible for antiresorptive therapy, clinical risk factors alone identified $6.5 \%$, and BMD plus clinical risk factors identified $28.6 \%$.

CONCLUSIONS: In addition to fracture risk factors present at BC diagnosis, cancer therapies leading to BMD loss further increase fracture risk. Evaluating both BMD and clinical risk factors may allow more effective identification of BC patients with elevated fracture risk.

British Journal of Cancer (2010) I 02, 645-650. doi:I0.1038/sj.bjc.6605548 www.bjcancer.com

Published online 19 January 2010

(c) 2010 Cancer Research UK

Keywords: bone mineral density (BMD); breast cancer; risk factors; fracture risk; guidelines; bone loss

Breast cancer (BC) is the most prevalent malignancy in women worldwide, with an estimated global incidence of more than 1.3 million new cases and nearly 465000 deaths in 2007 (Garcia et al, 2007). Improvements in detection of breast tumours over the last few decades have resulted in the early diagnosis of the majority of BCs, thus allowing more effective therapy (American Cancer Society, 2007). Expression of estrogen receptors (ERs) and/or progesterone receptors in tumour cells is a major determinant of systemic therapy - hormone-receptor (HR)-negative BCs are typically treated using cytotoxic chemotherapy, whereas endocrine therapy is the adjuvant therapy of choice for $\mathrm{HR}^{+}$tumours (Anderson et al, 2002; Early Breast Cancer Trialists' Collaborative Group (EBCTCG), 2005). However, both endocrine and cytotoxic therapies have known negative effects on bone health (Pfeilschifter and Diel, 2000).

Estrogen has a key role in preserving bone health in both premenopausal and postmenopausal women. After menopause, estrogen depletion is associated with increased rates of bone turnover, decreased bone mineral density (BMD), and altered microarchitecture in trabecular bone, leading to increased risk of fragility fractures (Wehrli et al, 2008). In addition to natural bone

*Correspondence: Dr P Hadji;

E-mail: hadji@med.uni-marburg.de

Received 29 September 2009; revised II December 2009; accepted I 8 December 2009; published online 19 January 2010 loss associated with ageing, therapies for BC can impair bone health directly, or indirectly by disrupting estrogen production and signalling (Pfeilschifter and Diel, 2000). For example, ovarian suppression using agents such as goserelin in premenopausal women, or aromatase inhibitor (AI) therapy in postmenopausal women, can result in substantial bone loss (Eastell et al, 2008; Gnant et al, 2008). Adjuvant AI therapy is now the standard of care for postmenopausal women with $\mathrm{HR}^{+} \mathrm{BC}$ because of its superior disease-free survival results and more favourable side-effect profile (particularly with regard to venous thrombosis and endometrial cancers) compared with tamoxifen (Howell et al, 2005; Thurlimann et al, 2005; Coombes et al, 2007). However, AIs vary in their ability to suppress estrogen levels in vivo (Geisler et al, 2008), and recent clinical trial data indicate that the near-complete estrogen suppression associated with letrozole treatment may further improve overall survival $v s$ tamoxifen in postmenopausal women with $\mathrm{HR}^{+}$BC (Mouridsen et al, 2009). Overall, the profound estrogen depletion achieved with AI therapy is associated with decreased BMD and increased fracture risk (Coombes et al, 2004; Howell et al, 2005; Thurlimann et al, 2005; Eastell et al, 2008). Cytotoxic chemotherapy can also impair bone health either directly, through effects on bone (e.g., methotrexate), or indirectly, through premature ovarian failure (Pfeilschifter and Diel, 2000; Shapiro et al, 2001). Overall, both natural and cancer treatmentinduced bone loss (CTIBL) can increase fracture risk in women with BC. 
Fortunately, several studies demonstrated the efficacy of antiresorptive agents such as bisphosphonates for preventing $\mathrm{BMD}$ loss and reducing fracture risk associated with $\mathrm{BC}$ therapy (Gnant et al, 2008; Lester et al, 2008; Brufsky et al, 2009). For example, in the ABCSG-12 study $(N=1803)$ in premenopausal women receiving ovarian suppression plus endocrine therapy for early stage $\mathrm{BC}$, patients receiving concomitant zoledronic acid (4 mg every 6 months) for 3 years maintained BMD during the treatment period compared with a significant BMD loss in patients who did not receive bisphosphonates $(-11.3 \%$ at lumbar-spine (LS), $-7.3 \%$ at hip; $P<0.0001$ for both) (Gnant et al, 2008). Two years after therapy cessation, patients who had received zoledronic acid experienced increases in BMD $(+4.0 \%$ at $\mathrm{LS}, P=0.022$; $+3.9 \%$ at hip, $P=0.073$ ), but BMD remained below baseline levels in the patients who did not receive zoledronic acid $(-6.3 \%$ at LS, $P=0.001 ;-4.1 \%$ at hip, $P=0.058$ ) (Gnant et al, 2008). In the Z-FAST study $(N=602)$ at 36 months, postmenopausal women receiving zoledronic acid (4 mg every 6 months) at the start of adjuvant $\mathrm{AI}$ therapy had significant increases in BMD $(+3.7$ at LS, $+1.7 \%$ at hip; $P<0.0001$ for both) compared with significant BMD losses $(-3.0 \%$ at LS, $-3.6 \%$ at hip; $P<0.0001$ for both) in patients for whom zoledronic acid initiation was delayed (Brufsky et al, 2009). In the ARIBON study $(N=131)$, postmenopausal women receiving AI therapy plus ibandronate ( $150 \mathrm{mg}$ monthly) experienced significant increases in BMD compared with placebo $(+3.0 \%$ vs $-3.2 \%$ at LS, $P=0.002 ;+0.6 \%$ vs $-3.9 \%$ at hip, $P=0.003$ ) (Lester et al, 2008). To date, there has not been a direct comparison of bisphosphonate BMD effects in the BC setting.

Established society guidelines for managing bone health in women with $\mathrm{BC}$ recommend the use of BMD measurements to identify candidates for preventive bisphosphonate therapy, with additional risk factors used only to identify high-risk patients who require close follow-up with dual-energy X-ray absorptiometry (DXA) (Hillner et al, 2003). This essentially limits bone-protective therapy to patients with DXA confirmation of osteoporosis (i.e., $T$-score $\leqslant-2.5)$. Unfortunately, DXA scanning of all patients might not be feasible in some settings. However, additional factors, including family and personal history of fragility fractures, age, long-term medications such as corticosteroids, low body mass index (BMI), and smoking, have all been associated with an increased fracture risk that is independent of BMD (Cummings et al, 1995; Kanis et al, 2005, 2007; Siris et al, 2006). To place BMD and other risk factors in the context of identifying women with $\mathrm{BC}$ who are at increased risk of fracture and are likely to benefit most from bisphosphonate therapy, a panel of experts recently evaluated data from large clinical trials in postmenopausal women and women with $\mathrm{BC}$ to develop international guidelines for using clinical risk factors for fracture along with BMD measurements (when available) (Hadji et al, 2008). To date, these emerging international guidelines have not been validated for fracture prevention in a prospective trial. Therefore, the purposes of the present single-institution study are two-fold: first, to evaluate the baseline BMD status of premenopausal and postmenopausal women with $\mathrm{BC}$ and the prevalence of baseline fracture risk factors in postmenopausal women with $\mathrm{BC}$; second, to use these baseline data to compare current society guidelines with the non$\mathrm{BMD}$-dependent guidance for fracture risk assessment in postmenopausal patients with BC.

\section{MATERIALS AND METHODS}

\section{Patients}

Premenopausal and postmenopausal women with $\mathrm{BC}$ and healthy women without $\mathrm{BC}$ (control group) were identified from patients treated at the gynaecological department of the Philipps-University of Marburg between 2003 and 2006. Premenopausal patients were defined as those having current menses, or estradiol levels greater than $20 \mathrm{pg} \mathrm{ml}^{-1}$ and follicle-stimulating hormone levels $<15 \mathrm{pg} \mathrm{ml}^{-1}$. The two groups $(N=1184)$ were matched according to the following criteria: age ( \pm 9 years), weight $( \pm 16 \mathrm{~kg})$, height $( \pm 13 \mathrm{~cm})$, BMI $\left( \pm 3 \mathrm{~kg} \mathrm{~m}^{-2}\right)$, hormone replacement therapy (HRT) use $(1: 1)$, and smoking $(1: 1)$. The final analysis included 88 pairs of patients and controls in the premenopausal cohort and 402 pairs in the postmenopausal cohort. All women completed a detailed questionnaire that identified all relevant risk factors for osteoporosis. The study was conducted in accordance with the Declaration of Helsinki and in accordance with the local ethical committee of the Philipps-University of Marburg.

\section{BMD assessment}

Bone mineral density was measured by the same operator by DXA with a Lunar Prodigy densitometer (GE/Lunar Healthcare Corporation, Madison, WI, USA) using a standard protocol for the femoral neck (FN), total hip (TH), and LS. The mean interval between BC diagnosis and baseline BMD assessment was approximately 15 days for both premenopausal and postmenopausal patients.

\section{Guideline comparison and estimation of fracture prevention}

Recommendations for managing bone health in women with $\mathrm{BC}$ were obtained from the American Society of Clinical Oncology (ASCO) guidelines (Hillner et al, 2003), and the emerging international guidelines were obtained from an expert panel of oncologists and endocrinologists (Hadji et al, 2008). Baseline data from postmenopausal women with $\mathrm{BC}$ included in this chart review were assessed according to the ASCO and emerging international guidelines to determine which patients would be eligible to receive bisphosphonate therapy. Fracture prevention was estimated based on fracture data recorded in the National Osteoporosis Risk Assessment (NORA) study in postmenopausal women (Siris et al, 2004) using the treatment criteria outlined in the ASCO guidelines ( $T$-score $\leqslant-2.5$ ) (Hillner et al, 2003), and the emerging international guidelines $(T$-score $<-2.0$ or at least two risk factors including $T$-score $<-1.5$, age $>65$ years, low BMI $\left(<20 \mathrm{~kg} \mathrm{~m}^{-2}\right)$, family history of hip fracture, personal history of fragility fracture after 50 years of age, oral corticosteroid use $>6$ months, and smoking) (Hadji et al, 2008). For this estimation, it was assumed that patients who would have received therapy according to either of the evaluation criteria would be protected from fracture. Although this is a crude estimate, it may approximate the relative protection afforded by the ASCO and emerging international guidelines, but does not consider the relative efficacy of bisphosphonate therapy.

\section{Statistical analyses}

Data analysis was carried out using SPSS version 12.0 to test differences in the mean values between groups using the $t$-test for parametric, the $U$-test for nonparametric, and the $\chi^{2}$ test for categoric variables.

\section{RESULTS}

\section{Baseline patient characteristics}

Among 88 pairs of premenopausal women ( 88 with $\mathrm{BC}$ and 88 controls) and 402 pairs of postmenopausal women (402 with BC and 402 controls), baseline characteristics were well balanced (Table 1). Overall, $5.8 \%$ of premenopausal women and $41.7 \%$ of postmenopausal women had received previous HRT. No women in the control group were receiving cancer therapies, whereas $\mathrm{BC}$ 
Table I Baseline characteristics of matched patient groups

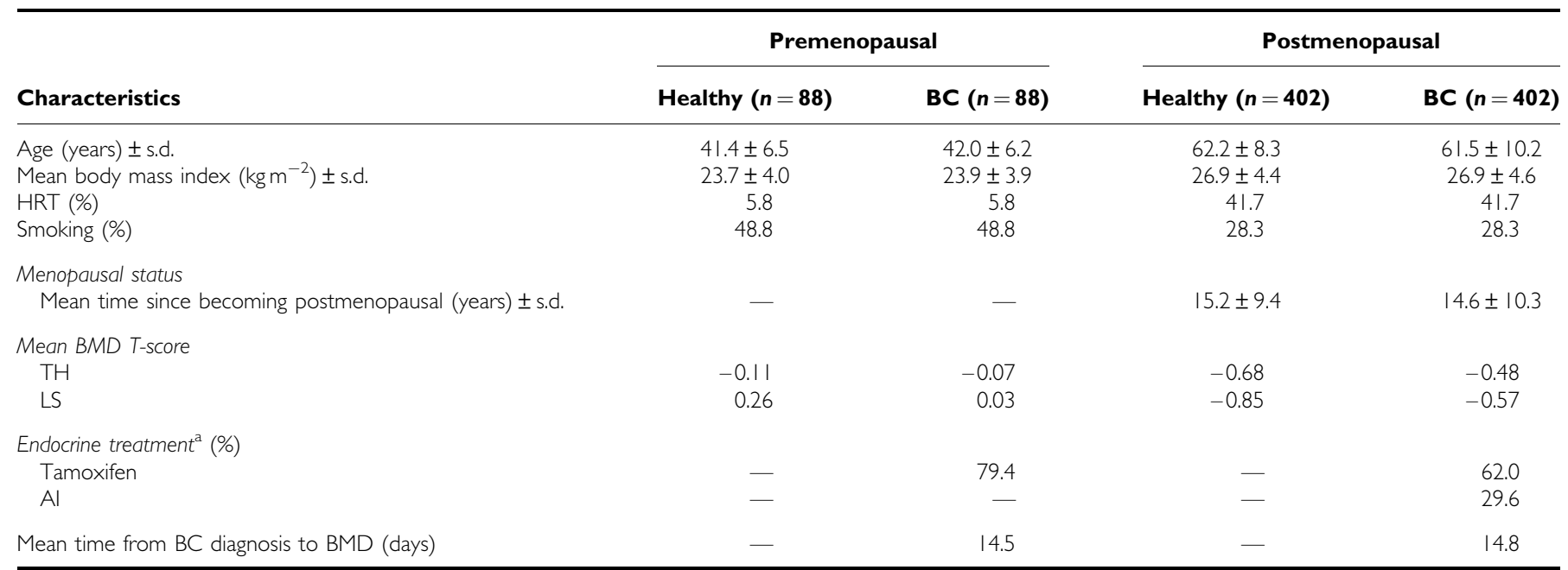

Abbreviations: $\mathrm{Al}=$ aromatase inhibitor, $\mathrm{BC}=$ breast cancer, $\mathrm{BMD}=$ bone mineral density; HRT = hormone replacement therapy; $\mathrm{LS}=$ lumbar-spine; s.d. = standard deviation; $\mathrm{TH}=$ total-hip. ${ }^{a}$ Patients not identified as receiving endocrine treatment had hormone-receptor-negative breast cancer.

patients were undergoing standard chemotherapy or endocrine therapies that suppressed estrogen levels (i.e., tamoxifen or an AI, such as anastrozole, letrozole, or exemestane). Endocrine treatment was recorded for $79.4 \%$ of premenopausal (tamoxifen) and $91.6 \%$ of postmenopausal patients (tamoxifen or AI). Stratification by ER status revealed $\mathrm{ER}^{+} \mathrm{BC}$ in 74 and $80 \%$ of the premenopausal and postmenopausal women, respectively.

\section{Prevalence of osteopenia, osteoporosis, and fracture risk factors}

Among women in the control groups, the prevalence of low BMD (osteopenia or osteoporosis) was substantially higher in the postmenopausal group $(\geqslant 43 \%)$ compared with the premenopausal group $(\leqslant 25 \%)$ at all sites (FN, TH, and LS). All BC patients underwent BMD measurement shortly after diagnosis. The mean time between diagnosis and BMD measurement was 14.5 days for premenopausal and 14.8 days for postmenopausal women. Similar to patients in the control groups, the prevalence of low BMD among patients with BC was higher among postmenopausal compared with premenopausal groups. Measurements of BMD at LS (Figure 1A) and $\mathrm{TH}$ (Figure 1B) in patients with $\mathrm{ER}^{+} \mathrm{BC}$ revealed normal BMD in more premenopausal patients compared with postmenopausal patients ( $>80 v s \sim 60 \%)$. A similar BMD pattern was seen in women with $\mathrm{ER}^{-}$tumours (data not shown). The overall incidence of osteopenia was $17 \%$ in premenopausal and $36 \%$ in postmenopausal patients with $\mathrm{ER}^{+} \mathrm{BC}$, whereas the corresponding osteoporosis rates were 1 and $6 \%$, respectively. Stratification of patients by ER status revealed higher prevalence of LS osteopenia in premenopausal patients with $\mathrm{ER}^{-} v s \mathrm{ER}^{+} \mathrm{BC}$ (18.2 vs 15.4\%; Figure 2A), whereas LS osteopenia was more prevalent in postmenopausal patients with $\mathrm{ER}^{+} v s \mathrm{ER}^{-} \mathrm{BC}(35.9 v s$ $22.4 \%$, respectively; Figure 2B). Moreover, LS osteoporosis was also more prevalent in postmenopausal patients with $\mathrm{ER}^{+} v s \mathrm{ER}^{-}$ BC (3.1 vs 1.3\%; Figure 2B). The prevalence of clinical factors associated with increased fracture risk independent of BMD is presented in Table 2 (Cummings et al, 1995; Kanis et al, 2005, 2007; Siris et al, 2006; Hadji et al, 2008). Except for age ( $>65$ years), history of smoking $(\sim 28 \%)$, and AI therapy $(\sim 30 \%)$, each validated fracture risk factor had low prevalence $(<6 \%)$ among postmenopausal patients with $\mathrm{ER}^{+} \mathrm{BC}$; however, $44.4 \%$ of these patients had $T$-scores $<-1.5$.
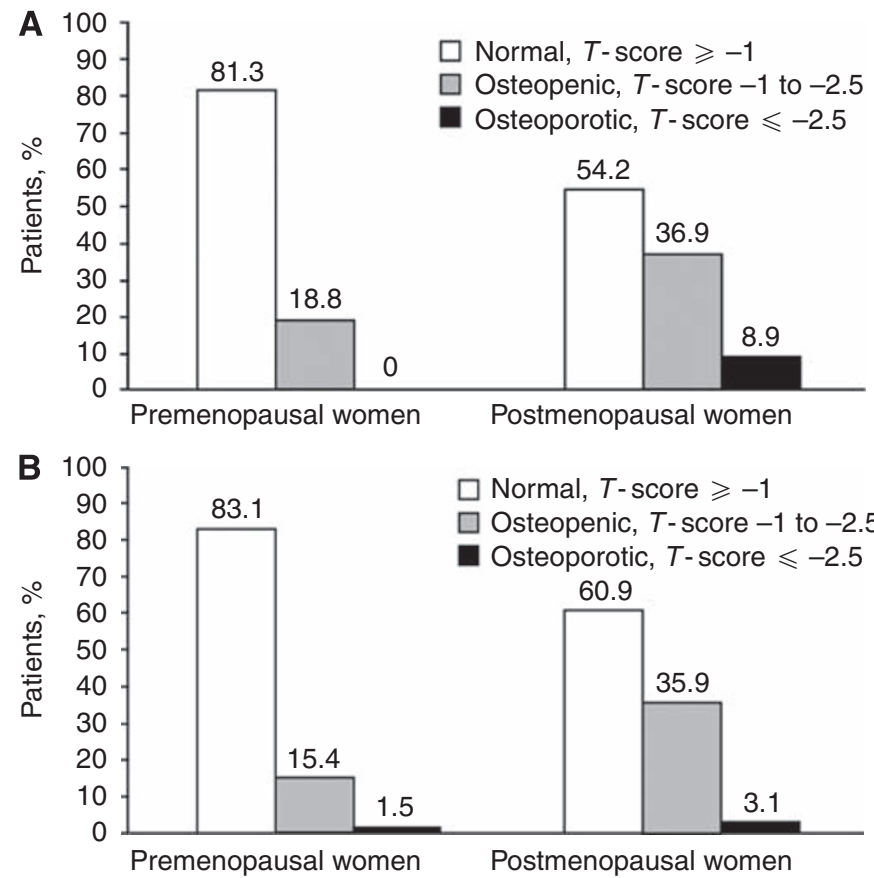

Figure I Prevalence of osteopenia and osteoporosis at (A) lumbarspine and (B) total-hip in women with estrogen-receptor (ER)-positive breast cancer.

\section{Assessment of the need for treatment and fracture risk using current and emerging international guidelines}

Current guidelines from ASCO recommend BMD screening for all women receiving AI therapy and antiresorptive agents for women with $T$-scores $\leqslant-2.5$ (Hillner et al, 2003). Applying ASCO guidelines to the $\mathrm{ER}^{+}$patient population in this study (i.e., the patients most likely to receive AIs), $8.9 \%$ of the postmenopausal patients would be eligible for bisphosphonate therapy (Figure $3 \mathrm{~A}$ ) (Siris et al, 2004). In contrast, applying the criteria from emerging 

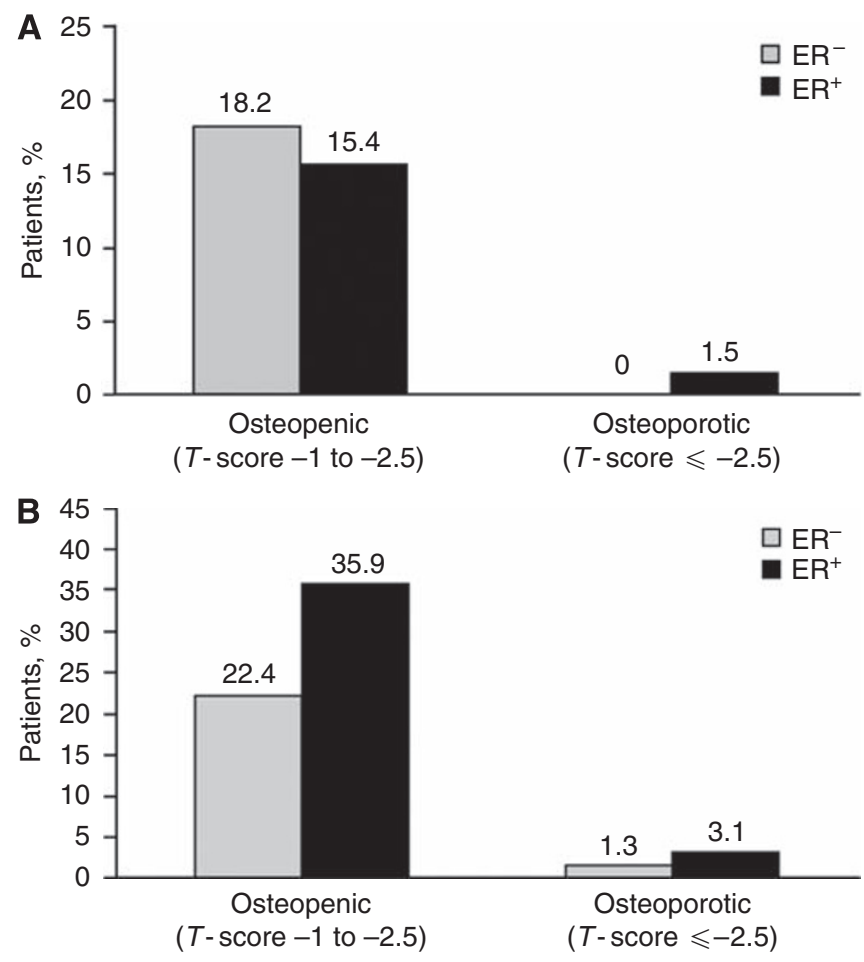

Figure 2 Prevalence of osteopenia and osteoporosis at the lumbarspine in (A) premenopausal and $(\mathbf{B})$ postmenopausal women with breast cancer, by estrogen-receptor (ER) status.

Table 2 Clinical risk factors for fracture and their prevalence in postmenopausal women with estrogen-receptor-positive $\left(E R^{+}\right)$breast cancer

\begin{tabular}{|c|c|c|}
\hline \multirow[b]{2}{*}{ Risk factors } & \multicolumn{2}{|c|}{ Patients } \\
\hline & Evaluable, $n$ & $\begin{array}{c}\text { Risk-factor- } \\
\text { positive, } \\
\text { n (\%) }\end{array}$ \\
\hline \multicolumn{3}{|l|}{ Validated $^{\mathrm{a}}$} \\
\hline T-score $<-1.5$ & 322 & $143(44.4)$ \\
\hline Age $>65$ years & 322 & $131(40.7)$ \\
\hline Low BMI $\left(<20 \mathrm{~kg} \mathrm{~m}^{-2}\right)$ & 322 & $10(3.1)$ \\
\hline Family history of hip fracture & 322 & $9(2.8)$ \\
\hline $\begin{array}{l}\text { Personal history of fragility fracture after } \\
\text { age } 50 \text { years }\end{array}$ & 322 & $18(5.6)$ \\
\hline Oral corticosteroid use $>6$ months & 322 & $2(0.6)$ \\
\hline Smoking & 378 & $107(28.3)$ \\
\hline Al therapy & 284 & $84(29.6)$ \\
\hline \multicolumn{3}{|l|}{ Possible } \\
\hline Chemotherapy & 402 & $148(36.8)$ \\
\hline
\end{tabular}

Abbreviations: $\mathrm{Al}=$ aromatase inhibitor; $\mathrm{BMI}=$ body mass index; $\mathrm{ER}=$ estrogen receptor. ${ }^{a}$ Validated in large clinical trials of healthy postmenopausal women (except Al therapy) (Cummings et al, 1995; Kanis et al, 2005, 2007; Siris et al, 2006; Hadji et al, 2008). ${ }^{b}$ Could not be validated because of insufficient trial data.

international guidelines for managing $\mathrm{AI}$-associated bone loss (AIBL; i.e., $T$-score $<-2.0$ and $\geqslant 2$ clinical risk factors including $T$-score $<-1.5$ ) (Hadji et al, 2008) identified more women who should receive antiresorptive therapy. Although clinical risk
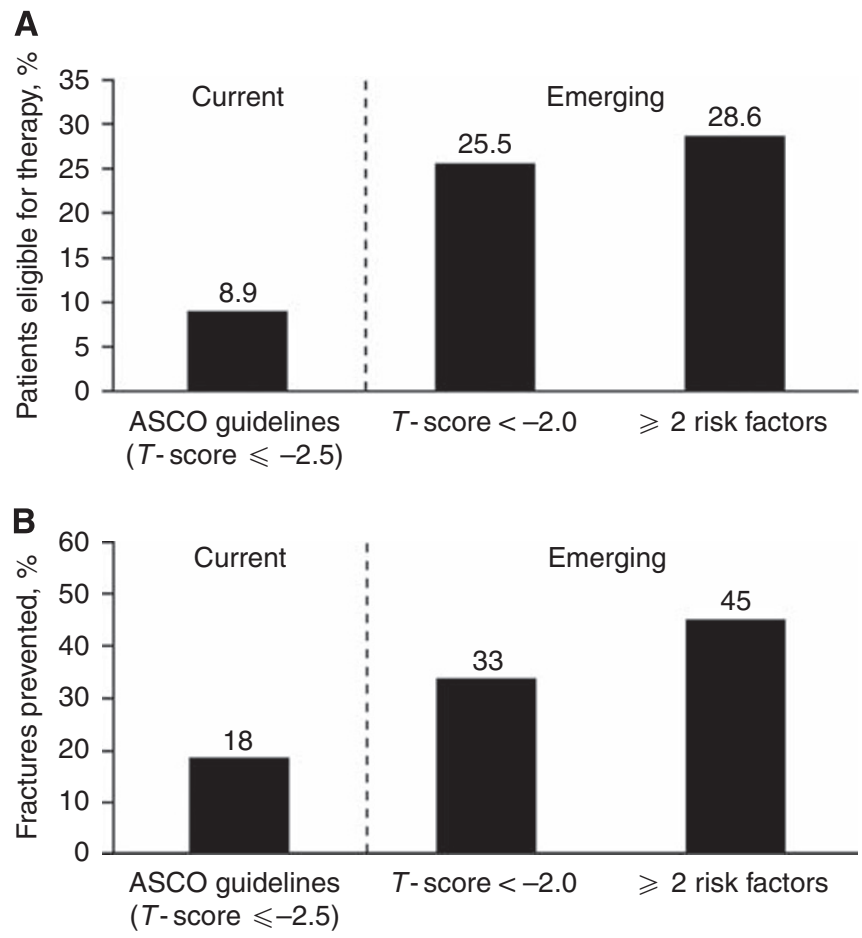

Figure 3 (A) Proportion of patients eligible for antiresorptive therapy and (B) estimation of the percentage of fractures prevented based on fracture-risk assessment using current (American Society of Clinical Oncology (ASCO)) and emerging international guidelines. Estimates based on fractures recorded in the National Osteoporosis Risk Assessment (NORA) study (Siris et al, 2004)

factors alone (i.e., not including $T$-score) identified $6.5 \%$ of postmenopausal patients with $\mathrm{ER}^{+} \mathrm{BC}$ in this study as eligible for bisphosphonate treatment, $25.5 \%$ of these patients would be eligible for treatment using $T$-score $<-2.0$ as the sole criterion. However, selecting patients with two or more clinical risk factors (including $T$-score $<-1.5$ ) identified a somewhat larger proportion of patients $(28.6 \%)$ who would be eligible for treatment (Figure 3A) (Siris et al, 2004). Based on NORA fracture incidence data from 170083 women (Siris et al, 2006), limiting bisphosphonate treatment according to current ASCO guidelines is estimated to prevent only $18 \%$ of potential fractures, whereas treatment based on emerging international guidelines would prevent approximately $45 \%$ of potential fractures (Figure 3B) (Siris et al, 2004).

\section{DISCUSSION}

Decreased BMD and increased fracture risk are well-documented adverse events associated with BC therapies (Pfeilschifter and Diel, 2000; Hadji, 2009). Bisphosphonates have an established role in treating postmenopausal osteoporosis and have demonstrated clinical benefits for preventing bone loss during therapy for BC (Coleman, 2008; Hadji, 2009). The largest body of evidence to date is for twice-yearly intravenous zoledronic acid $(4 \mathrm{mg})$, which can prevent bone loss and improve BMD in premenopausal and postmenopausal women receiving adjuvant endocrine therapy for BC (total $N=2598$ ) (Schenk et al, 2007; Brufsky et al, 2008; Gnant et al, 2008).

In Europe, current Arbeitsgemeinschaft Gynäkologische Onkologie e.V. (AGO) guidelines (www.ago-online.de) support the use 
of bisphosphonates to prevent and treat bone loss during adjuvant therapy for BC but do not specify a threshold for intervention, whereas the St. Gallen Expert Consensus does not recommend routine bisphosphonate use in women receiving AIs who have normal bone health (Goldhirsch et al, 2009). Current ASCO guidelines depend on osteoporotic BMD T-scores to identify patients with early $\mathrm{BC}$ who are eligible for bone-targeted therapy (Hillner et al, 2003). However, the majority of fractures occur in women who are osteopenic (BMD - 1.0 to -2.5) (Siris et al, 2004), and treatment based on current guidelines will not prevent fractures in these women. Recent emerging international guidelines for bone health management in postmenopausal women receiving $\mathrm{AI}$ therapy for $\mathrm{BC}$ has now expanded the treatment criteria to include clinical risk factors in addition to BMD to guide therapy (Hadji et al, 2008).

The purpose of our study was to assess baseline characteristics in women with newly diagnosed BC and determine the proportion of patients who would receive bisphosphonate therapy based on ASCO and emerging international guidelines (Hillner et al, 2003; Hadji et al, 2008). In addition, because fracture data were unavailable for our patients, we estimated the proportion of patients in each group who would experience a fracture by comparing baseline data in our patients with fracture data from the NORA study. Results from our study indicate that the emerging international guidelines (BMD + clinical risk factors) may identify more patients likely to benefit from bisphosphonate therapy. Initiating bisphosphonate treatment according to emerging international guidelines is predicted to prevent $45 \%$ of potential fractures in postmenopausal patients $v s \quad 18 \%$ for treatment initiated per ASCO guidelines (Figure 3B) (Siris et al, 2004). These estimates are based on data from the NORA study showing that although $33 \%$ of fractures occurred in women with $T$-scores $\leqslant-2.0$, only $18 \%$ occurred in women with osteoporotic BMD values ( $T$-score $\leqslant-2.5$ ), indicating that a large proportion of patients experience a fracture before developing osteoporosis (Siris et al, 2004). Additional data from the NORA study indicate that at least $45 \%$ of fractures occur in women with two or more fracture risk factors. It is important to note that our estimates of fracture prevention are based on fracture risk in healthy women (Siris et al, 2006) and might therefore underestimate the true protective effect of bisphosphonates in the BC setting.

Results from our study indicate that both premenopausal and postmenopausal women with BC may already have low BMD or develop this condition soon after BC diagnosis. Furthermore, because BMD measurement occurred within a short time from BC diagnosis $(\sim 15$ days $)$ in this study, bone loss that would occur during $\mathrm{BC}$ treatment is not considered. For example, AIBL and ovarian suppression-associated bone loss are most severe within the first 3 years of beginning therapy, but remain elevated for the duration of therapy (Howell et al, 2005; Thurlimann et al, 2005; Coombes et al, 2007; Eastell et al, 2008; Gnant et al, 2008). Therefore, patients are likely to experience additional decreases in BMD during $\mathrm{BC}$ treatment, making the management of bone health an increasing concern. This is especially true for postmenopausal

\section{REFERENCES}

American Cancer Society (2007) Breast Cancer Facts \& Figures 2007-2008. American Cancer Society, Inc: Atlanta, GA

Anderson WF, Chatterjee N, Ershler WB, Brawley OW (2002) Estrogen receptor breast cancer phenotypes in the Surveillance, Epidemiology, and End Results database. Breast Cancer Res Treat 76(1): $27-36$

Brufsky A, Bundred N, Coleman R, Lambert-Falls R, Mena R, Hadji P, Jin L, Schenk N, Ericson S, Perez EA (2008) Integrated analysis of zoledronic acid for prevention of aromatase inhibitor-associated bone loss in postmenopausal women with early breast cancer receiving adjuvant letrozole. Oncologist 13(5): 503-514 patients with $\mathrm{ER}^{+} \mathrm{BC}$, in whom osteopenia and osteoporosis were more prevalent at baseline. Approximately 30\% $(n=84)$ of postmenopausal women with $\mathrm{ER}^{+} \mathrm{BC}$ were scheduled to receive AI treatment, which might further exacerbate bone loss in this group over time.

Recently, the FRAX Web-based tool (www.shef.ac.uk/FRAX/ index.htm) was developed by the World Health Organization to evaluate fracture risk in healthy women based on individual patient models integrating clinical risk factors and FN BMD. These data are used to calculate the 10-year probability of hip fracture or any major osteoporotic fracture (forearm, hip, shoulder, or clinically overt in spine), with or without BMD measurements. However, because the FRAX tool does not permit including cancer therapy-associated bone loss as a variable in the fracture risk assessment, it will probably underestimate the absolute fracture risk for women with BC. Therefore, risk assessment tools such as FRAX may require specific adaptations for use in the $\mathrm{BC}$ population.

Our results in premenopausal and postmenopausal women with $\mathrm{BC}$ indicate that bone loss resulting in osteopenia and osteoporosis are relatively common in postmenopausal women with $\mathrm{ER}^{+} \mathrm{BC}$, who are likely to receive AI therapy. Because AIs are associated with increased risks of bone loss and fracture that persist for the duration of treatment, active management of bone health in this patient population is important. Using emerging international guidelines (Hadji et al, 2008) to initiate bisphosphonate therapy in these patients is predicted to prevent nearly half of all potential fractures. Recently developed fracture-risk evaluation tools and recommendations for monitoring bone health emphasise the importance of comprehensive fracture-risk assessment and the need for early intervention in women with BC. Future prospective studies will be needed to assess the benefits of bisphosphonate therapy for fracture prevention and to compare the relative efficacy of bisphosphonates in the adjuvant setting.

\section{ACKNOWLEDGEMENTS}

This work was not supported by any institutional or industrysponsored research grants. All analyses and conclusions were conducted and approved by the authors. Financial support for medical editorial assistance was provided by Novartis Pharmaceuticals. We thank Shalini Murthy, PhD, for her medical editorial assistance with this manuscript. Previous presentation: Partial data presentation in poster at EBCC 2008.

\section{Conflict of interest}

Dr Hadji has received honoraria, unrestricted educational grants, and research funding from the following companies: Amgen, AstraZeneca, Eli Lilly, GlaxoSmithKline, Novartis, Novo Nordisk, Organon, Pfizer, Procter \& Gamble, Roche, Sanofi-Aventis, Solvay, and Wyeth. Drs Ziller, Albert, and Kalder have no conflict of interest to declare.

Brufsky AM, Bosserman LD, Caradonna RR, Haley BB, Jones CM, Moore HC, Jin L, Warsi GM, Ericson SG, Perez EA (2009) Zoledronic acid effectively prevents aromatase inhibitor-associated bone loss in postmenopausal women with early breast cancer receiving adjuvant letrozole: Z-FAST study 36-month follow-up results. Clin Breast Cancer 9(2): $77-85$

Coleman RE (2008) Risks and benefits of bisphosphonates. Br J Cancer 98(11): $1736-1740$

Coombes RC, Hall E, Gibson LJ, Paridaens R, Jassem J, Delozier T, Jones SE, Alvarez I, Bertelli G, Ortmann O, Coates AS, Bajetta E, Dodwell D, Coleman RE, Fallowfield LJ, Mickiewicz E, Andersen J, Lonning PE, 
Cocconi G, Stewart A, Stuart N, Snowdon CF, Carpentieri M, Massimini G, Bliss JM (2004) A randomized trial of exemestane after two to three years of tamoxifen therapy in postmenopausal women with primary breast cancer. N Engl J Med 350(11): 1081-1092

Coombes RC, Kilburn LS, Snowdon CF, Paridaens R, Coleman RE, Jones SE, Jassem J, Van de Velde CJ, Delozier T, Alvarez I, Del Mastro L, Ortmann O, Diedrich K, Coates AS, Bajetta E, Holmberg SB, Dodwell D, Mickiewicz E, Andersen J, Lonning PE, Cocconi G, Forbes J, Castiglione M, Stuart N, Stewart A, Fallowfield LJ, Bertelli G, Hall E, Bogle RG, Carpentieri M, Colajori E, Subar M, Ireland E, Bliss JM (2007) Survival and safety of exemestane versus tamoxifen after 2-3 years' tamoxifen treatment (Intergroup Exemestane Study): a randomised controlled trial. Lancet 369(9561): 559-570

Cummings SR, Nevitt MC, Browner WS, Stone K, Fox KM, Ensrud KE, Cauley J, Black D, Vogt TM (1995) Risk factors for hip fracture in white women. Study of Osteoporotic Fractures Research Group. N Engl J Med 332(12): $767-773$

Early Breast Cancer Trialists' Collaborative Group (EBCTCG) (2005) Effects of chemotherapy and hormonal therapy for early breast cancer on recurrence and 15-year survival: an overview of the randomised trials. Lancet 365(9472): $1687-1717$

Eastell R, Adams JE, Coleman RE, Howell A, Hannon RA, Cuzick J, Mackey JR, Beckmann MW, Clack G (2008) Effect of anastrozole on bone mineral density: 5-year results from the anastrozole, tamoxifen, alone or in combination trial 18233230. J Clin Oncol 26(7): 1051-1058

Garcia M, Jemal A, Ward EM, Center MM, Hao Y, Siegel RL, Thun MJ (2007) Global Cancer Facts \& Figures 2007. American Cancer Society: Atlanta, GA

Geisler J, Helle H, Ekse D, Duong NK, Evans DB, Nordbo Y, Aas T, Lonning PE (2008) Letrozole is superior to anastrozole in suppressing breast cancer tissue and plasma estrogen levels. Clin Cancer Res 14(19): $6330-6335$

Gnant M, Mlineritsch B, Luschin-Ebengreuth G, Kainberger F, Kassmann H, Piswanger-Solkner JC, Seifert M, Ploner F, Menzel C, Dubsky P, Fitzal F, Bjelic-Radisic V, Steger G, Greil R, Marth C, Kubista E, Samonigg H, Wohlmuth P, Mittlbock M, Jakesz R (2008) Adjuvant endocrine therapy plus zoledronic acid in premenopausal women with early-stage breast cancer: 5-year follow-up of the ABCSG-12 bone-mineral density substudy. Lancet Oncol 9(9): 840-849

Goldhirsch A, Ingle JN, Gelber RD, Coates AS, Thurlimann B, Senn HJ (2009) Thresholds for therapies: highlights of the St Gallen International Expert Consensus on the primary therapy of early breast cancer 2009. Ann Oncol 20(8): 1319-1329

Hadji P (2009) Aromatase inhibitor-associated bone loss in breast cancer patients is distinct from postmenopausal osteoporosis. Crit Rev Oncol Hematol 69(1): 73-82

Hadji P, Body JJ, Aapro MS, Brufsky A, Coleman RE, Guise T, Lipton A, Tubiana-Hulin M (2008) Practical guidance for the management of aromatase inhibitor-associated bone loss. Ann Oncol 19(8): 1407-1416

Hillner BE, Ingle JN, Chlebowski RT, Gralow J, Yee GC, Janjan NA, Cauley JA, Blumenstein BA, Albain KS, Lipton A, Brown S (2003) American Society of Clinical Oncology 2003 update on the role of bisphosphonates and bone health issues in women with breast cancer. J Clin Oncol 21(21): $4042-4057$
Howell A, Cuzick J, Baum M, Buzdar A, Dowsett M, Forbes JF, Hoctin-Boes G, Houghton J, Locker GY, Tobias JS (2005) Results of the ATAC (Arimidex, Tamoxifen, Alone or in Combination) trial after completion of 5 years' adjuvant treatment for breast cancer. Lancet 365(9453): 60 -62

Kanis JA, Borgstrom F, De Laet C, Johansson H, Johnell O, Jonsson B, Oden A, Zethraeus N, Pfleger B, Khaltaev N (2005) Assessment of fracture risk. Osteoporos Int 16(6): $581-589$

Kanis JA, Oden A, Johnell O, Johansson H, De Laet C, Brown J, Burckhardt P, Cooper C, Christiansen C, Cummings S, Eisman JA, Fujiwara S, Gluer C, Goltzman D, Hans D, Krieg MA, La Croix A, McCloskey E, Mellstrom D, Melton III LJ, Pols H, Reeve J, Sanders K, Schott AM, Silman A, Torgerson D, van Staa T, Watts NB, Yoshimura N (2007) The use of clinical risk factors enhances the performance of BMD in the prediction of hip and osteoporotic fractures in men and women. Osteoporos Int 18(8): $1033-1046$

Lester JE, Dodwell D, Purohit OP, Gutcher SA, Ellis SP, Thorpe R, Horsman JM, Brown JE, Hannon RA, Coleman RE (2008) Prevention of anastrozole-induced bone loss with monthly oral ibandronate during adjuvant aromatase inhibitor therapy for breast cancer. Clin Cancer Res 14(19): $6336-6342$

Mouridsen H, Giobbie-Hurder A, Goldhirsch A, Thurlimann B, Paridaens R, Smith I, Mauriac L, Forbes JF, Price KN, Regan MM, Gelber RD, Coates AS (2009) Letrozole therapy alone or in sequence with tamoxifen in women with breast cancer. $N$ Engl J Med 361(8): 766-776

Pfeilschifter J, Diel IJ (2000) Osteoporosis due to cancer treatment: pathogenesis and management. J Clin Oncol 18(7): 1570-1593

Schenk N, Lombart A, Frassoldati A, Neven P, Jerusalem G, Deleu I, Mebis J, Maerevoet M, Miller J, Dias R (2007) The E-ZO-FAST trial: zoledronic acid (ZA) effectively inhibits aromatase inhibitor associated bone loss (AIBL) in postmenopausal women (PMW) with early breast cancer (EBC) receiving adjuvant letrozole (LET). EJC Suppl 5: 186-187, (Abstr 2008)

Shapiro CL, Manola J, Leboff M (2001) Ovarian failure after adjuvant chemotherapy is associated with rapid bone loss in women with earlystage breast cancer. J Clin Oncol 19(14): 3306-3311

Siris ES, Brenneman SK, Barrett-Connor E, Miller PD, Sajjan S, Berger ML, Chen YT (2006) The effect of age and bone mineral density on the absolute, excess, and relative risk of fracture in postmenopausal women aged 50-99: results from the National Osteoporosis Risk Assessment (NORA). Osteoporos Int 17(4): 565-574

Siris ES, Chen Y-T, Abbott TA, Barrett-Connor E, Miller PD, Wehren LE, Berger ML (2004) Bone mineral density thresholds for pharmacological intervention to prevent fractures. Arch Intern Med 164(10): 1108-1112

Thurlimann B, Keshaviah A, Coates AS, Mouridsen H, Mauriac L, Forbes JF, Paridaens R, Castiglione-Gertsch M, Gelber RD, Rabaglio M, Smith I, Wardley A, Price KN, Goldhirsch A (2005) A comparison of letrozole and tamoxifen in postmenopausal women with early breast cancer. $N$ Engl $J$ Med 353(26): 2747-2757

Wehrli FW, Ladinsky GA, Jones C, Benito M, Magland J, Vasilic B, Popescu AM, Zemel B, Cucchiara AJ, Wright AC, Song HK, Saha PK, Peachey H, Snyder PJ (2008) In vivo magnetic resonance detects rapid remodeling changes in the topology of the trabecular bone network after menopause and the protective effect of estradiol. J Bone Miner Res 23(5): $730-740$ 